\title{
Effectiveness of Training of Spiritual Intelligence Components on consequences of psychological and self-esteem of Adolescents
}

\author{
Leila Mohaddeth Shakouri Ganjavi ${ }^{1 *}$
}

\section{ABSTRACT}

Objective: since transition from adolescence is accompanied by different types of stress and adolescents are more vulnerable due to physical, psychological and social matters, the present research was aimed to study the effectiveness of training of spiritual intelligence components on depression, anxiety, stress and self-esteem of adolescents. Methodology: the present research was conducted in the first half of the academic year 2014-2015. Moreover, it was quasiexperimental with pretest-posttest that used control group. Hence 40 of high school male students in Tehran were selected using convenience sampling method and located in experimental group and control group randomly $(n=20)$. Both the groups were pretested using demographic questionnaire, and scale of depression, anxiety and stress DASS-42, Rozenberg's self-esteem scale. Afterwards, the experimental groups were trained for 8 sessions under training of spiritual intelligence components and the control group received no intervention. In the following, both the groups were post-tested and the obtained data were analyzed using inferential and descriptive statistical methods accompanied by SPSS21 software. Findings: the findings indicated that training of spiritual intelligence components significantly reduces depression, anxiety, stress and increases self-esteem in adolescents. Conclusion: it can be concluded from the present research that due to the high level of effectiveness of training of spiritual intelligence components, its low cost and its high acceptability by the adolescents, especially when it is performing in group, it had a great positive impact on reduction of depression, anxiety and stress in adolescents.

Keywords: Spiritual Intelligence, Consequences Of Psychological, Self-Esteem, Adolescents.

Adolescence, according to what has been defined by WHO (2009), includes the years between 11 and 19. This age group faces with considerable physical, psychological and social changes in transition from childhood to adulthood. Moreover, stress factors in this age period have great effects on emergence of psychological disorders (Safar Alizadeh, Partov Azam and Habibpour,

\footnotetext{
${ }^{1}$ Master student of Psychology, Islamic Azad University International Center of Kish, Kish Island, Iran *Responding Author (C) 2016 I L Ganjavi; licensee IJIP. This is an Open Access Research distributed under the terms of the Creative Commons Attribution License (http://creativecommons.org/licenses/by/2.0), which permits unrestricted use, distribution, and reproduction in any Medium, provided the original work is properly cited.
} 


\section{Effectiveness of Training of Spiritual Intelligence Components on consequences of psychological and self-esteem of Adolescents}

2010). Hence paying special attention to factors that can have positive impact on psychological states, reduction of psychological distress and enhancement of physical and psychological health in adolescents are of great importance. One of the most important mental features which help individuals cope with ups and downs effectively and patiently and maintain their achieved abilities and values is "self-esteem" (Dianati, Dehkordi, Juybari, and Moradi, 2012). Self-esteem is highly important in terms of mental health and personality balance (Brown and Turner, 2010). Self-esteem is an intellectual evaluation based on the fact that every individual is valuable and, on the contrary, an individual is valueless and unpleasant (Kazemi, 2015). Low self-esteem disturbs humans' balance and dynamism, weakens their performance, reduces their efficiency, and affects their learning and creativity in a negative way, which is accompanied by fear (Parvin, 1998; cited in Kazeneini and Rajabi, 2012). On the contrary, high self-esteem results in positive and constructive strategies.

Tensions result in personal relationships, physical changes and unstable feelings in this age period can lead to variety of disorders in adolescents. Depression is one of the most prevalence and debilitating psychological issues in adolescence. It has such a comprehension prevalence among psychological disorder that it is called psychological colds (Mostafaie \& Bashirian, 2012). According to the related conducted studies in Iran, about $20 \%$ of the Iranian students deal with depression. For instance, Zargham indicated in a research in 1996 on an age group between 13 and 17 that $78 \%$ of female and $75 \%$ of male students have moderate to severe depression (cited in Safar Alizadeh et al., 2010). Depressed adolescents are too irritable and the distinction between depression, mood swings and symptoms of other diseases in them is very difficult. Depressed adolescents feel that they are not useful, attractive and valuable. Moreover, they feel that they have no future and they cannot reach to their goals (Habibpour \& Sharifi, 2008). Existence of such psychological moods in adolescence can be deemed as a ground work for failure and falling behind progress. Therefore, paying special attention to depression in adolescence are of great importance.

Anxiety is of other types of common disorders in adolescence which its prevalence has been reported to be between 10 and 20 percent (Kandal et al., 2010). Anxiety at the beginning of adolescence leads to emergence of sensitivity in interpersonal relationships and reduction of adjustment. Hence anxious adolescents experience more psychological issues and physical disease compared to their peers (Legrand, 2011). Conducted studies on "Prevalence of Anxiety Disorders" demonstrated that 5 to 10 percent of adolescents deals with one of the diagnostic criteria of anxiety disorder so that misadjusts normal life and daily function. In addition, anxiety can be accompanied by disadvantages such as reduction in self-esteem, feeling of incompetence, depression and insolvency, etc. (Kheirkhah, Makari, Neisani Samani and Hosseinin, 2013). Therefore, paying attention to effective variables on psychological disorders in adolescents is very important. 


\section{Effectiveness of Training of Spiritual Intelligence Components on consequences of psychological and self-esteem of Adolescents}

In addition, stress is among other prevalence psychological issues among adolescents. On other words, stress refers to experiencing occurances that is considered to be hazardous for physical or mental welfare of the person. There have been many investigations about prevalence of stress in adolescents (Asghari, Ghasemi, Yusefi, Sa’adat and Rafiee, 2015). Bahri Yousef (2010) indicated that prevalence of stress among students is about $26.1 \%$ which is a relatively high amount. Narimani and Ariapouran (2007) demonstrated in their study that familial stress factors, personal stress factors and educational stress factors have the greatest impact on stress in adolescents, respectively, among socio-psychological stress factors. Conducting studies on stress and stress factors among adolescents is significant due to the sensitivity related to adolescence and according to the high level of prevalence of stress among adolescents. However, one of the most important factors protecting humans against anxiety, stress, and stressful events is selfesteem. Self-esteem is an important variable which is related to different factors in life, affecting humans' obvious behaviors (Cooper Smith, 1967). And considering the fact that it includes the fourth need from Maslow's need hierarchy, it adds to people's confidence and independence (Frieson, 2008). Results obtained from many studies show that low self-esteem has consequences such as anxiety and depression (Kaplan, 2007), physical and psychological disorders (Khodabakhshi et al, 2015), communicational and behavioral problems and perverted behaviors (Kaplan, 2007). Therefore, this item requires special attention especially when it comes to adolescents with irresponsible parents or no parents.

Therefore, according what has been said, paying special attention to performance of psychological interventions which can provide groundwork for reduction of related disorders among adolescents. This is while spiritual intelligence is among the most prominent aspects of human existence which has a close relationship with many aspects of his health, growth and evolution (Charkhabi et al., 2014). In definition of human existence dimensions, WHO points to spiritual dimension in addition to social, psychological and physical dimensions (cited in Moshiri \& Vashyst, 2014). Spiritual intelligence refers to human's capacity and ability to experience something between us and the world we live in simultaneously and seamlessly (Gain \& Purohit, 2011). Moreover, it refers to the possibility of acquiring more knowledge and understanding as well as providing necessary background to achieve perfection and progress in life (Charkhabi et al., 2014). It has been indicated in many studies that there is a relationship between spiritual intelligence and different aspects of one’s health (Charkhabi et al., 2014; Moshiri \& Vashyst, 2014; Gain \& Purohit, 2011). Moreover, there is a significant relationship between spiritual intelligence and reduction of psychological issues in adolescents (Saber Amanian, 2014). Therefore, it can be predicted that training the components of spiritual intelligence has significant impact on reduction of psychological disorders such as depression, anxiety and stress in adolescents. Hence the necessity to conduct a precise study is revealed. On the other hand, according to the conducted researches in Iran, there has been no relevant study on effectiveness of the components of spiritual intelligence on reduction of psychological disorders such as depression, anxiety and stress in adolescents. Therefore, in order to address this research gap in 


\section{Effectiveness of Training of Spiritual Intelligence Components on consequences of psychological and self-esteem of Adolescents}

Iran and also promotion of psychological health in adolescents, such an investigation seems to be necessary. According to what has been mentioned above, the present research is going to study the effectiveness of training of spiritual intelligence components on self-esteem and depression, anxiety, stress of adolescents.

\section{METHODOLOGY}

The present research was quasi-experimental with pretest-posttest that used control group. The population consisted of all male high school students in Tehran in the first half of the academic year 2014-2015. According to the fact that the minimum sample population in the experimental studies should be 15 individuals, a 15-individual sample size was chosen for each of the groups. Afterwards, in order to increase the statistical power and to manage the reduced number of participants, a 20-individual sample size $(n=20)$ was chosen for each of the groups. The sampling was based on convenience sampling method using all male high school students in Tehran.

The inclusion criteria of the present study were informed satisfaction and willingness to participate in the research, ability to participate in sessions and cooperation in doing assignments, willingness to cooperate in completing instruments, physical and psychological stability and the age range between 14 and 18. In addition, the exclusion criteria for this study were lack of willingness to participate in the research and absence of more than three sessions in the training process, lack of ability to take part in the sessions and lack of ability to cooperation in doing assignments and receiving any kind of training and psychological treatment out of the schedule and program set in the research.

\section{Instruments}

The instruments used in the present research consisted of demographic questionnaire, and scale of depression, anxiety and stress DASS-42.

Demographic questionnaire: this questionnaire was formulated in order to receive the personal information of participants. Characteristics such as age, gender, education and marital status were questioned in the questionnaire.

Depression, anxiety and stress scale (DASS-42): depression, anxiety and stress scale (DASS-42) was developed in 1995 by Lovibond and Lovibond (Henry \& Crawford, 2005). This scale consisted of two forms. Short-form consisted of 21 items which evaluates each of the variables of depression, anxiety and stress by seven expressions. The way of answering is based on 4-choice questions ( $0=$ never to $3=$ so much). Question distribution is as follows: 14 questions for depression, 14 questions for anxiety and 14 questions for stress. The longform consisted of 42 items (14 variables for each variable). This scale is based on Likert scale including no, low, medium and high. The minimum score for each question is zero and the maximum score is three. Eventually, the summation of scores of depression, anxiety and stress is calculated for each patient. The reliability of the scale was calculated to be 0.91 , 0.84 and 0.90 for the variables of depression, anxiety and stress, respectively using 


\section{Effectiveness of Training of Spiritual Intelligence Components on consequences of psychological and self-esteem of Adolescents}

Cronbach's alpha method. The short-form of the scale was validated by Sahebi et al. (2005; cited in Bayazi, 2012) for Iranian population and the internal consistency of this scale was $0.77,0.79$ and 0.78 for the variables of depression, anxiety and stress, respectively using Cronbach's alpha method. Moreover, Hanifi, Bahraminezhad, Mirza Khalil Abadi, Ahmadi, Khani and Taran conducted a study entitled "The impact of familiarization programs on stress, anxiety and depression of patients under coronary angiography" and calculated the reliability of the scale to be $0.95,0.89$ and 0.99 for the variables of anxiety, stress and depression, respectively.

Rozenberg's Self-esteem scale: Rozenberg's self-esteem scale which was made by Rosenberg in 1965 and translated by Rajabi and Bohlul in 2008 measures general selfesteem and personal value. This scale included 10 general items which measure life satisfaction and having a good feeling about oneself (Safaralizadeh, Partoazam, and Habibpour, 2001). According to Bornet \& Right (2002; according to Rajabi and Bohlul, 2008), Rozenberg's self-esteem scale (SES) is one of the most common scales for measuring self-esteem; and it is a well-recognized scale, because, for self-esteem, it uses a concept similar to the concept presented in psychological theories about oneself. SES has been formed in order to give a general image of positive and negative attitudes to oneself (Rosenberg, 1979, according to Bashlideh, Yousefi, Haghighi et al, 2013). Using Cronbach's alpha, Rosenberg reported the reliability of the questionnaire to be 0.89 . This scale has stronger correlation coefficients than Cooper Smith's self-esteem questionnaire (SEI); and when measuring the levels of self-esteem, it has greater validity (Grifits et al, 1997, according to Rajabi and Bohlul, 2008). In order to perform this test, the scale was given to respondents; and the respondents were asked to announce their agreement or disagreement by selecting choices such as "I agree" or "I disagree". Rosenberg reported the reformation of the scale to be 0.9 and the scalability of the scale to be 0.7 (Makund Hosseini, 2014). Cronbach's alpha coefficient for this scale, in the first turn, was 0.87 for men and 0.86 for women; and in the second turn, it was 0.88 for men and 0.87 for women. The correlation of retest was in a range of 0.82 and 0.88 , and internal consistency coefficient or Cronbach's alpha was in a range of 0.77 and 0.88 (Newton et al, 1999, according to Bashlideh, Yusefi, Haghighi et al, 2013). This scale had acceptable validity (0.77).

Statistical Package of Social Sciences (SPSS-21) software was utilized in order to analyze the obtained data. In order to analyze research data, based on descriptive statistics, indices of average standard deviation, frequency and frequency percentage were used. Moreover, based on inferential statistics, Analysis of Covariance (ANCOVA) was used. 
Effectiveness of Training of Spiritual Intelligence Components on consequences of psychological and self-esteem of Adolescents

Table 1: cognitive-behavioral group therapy training protocol

\begin{tabular}{|c|c|}
\hline Session & Subject \\
\hline First & $\begin{array}{l}\text { Implementation of pre-test, member familiarity with each other, members familiarity } \\
\text { with the overall structure of the meetings, defining feature of spiritual intelligence } \\
\text { and its components, notification of stress and stress responses, muscle relaxation and } \\
\text { slow breathing training. }\end{array}$ \\
\hline Second & $\begin{array}{l}\text { Benefits of spiritual intelligence and its components and improvement of daily } \\
\text { interactions, to train relaxation and slow breathing to the students. }\end{array}$ \\
\hline Third & $\begin{array}{l}\text { Describe the relationship between thoughts and psychological well-being, to train } \\
\text { mental imagery exercises to the participants, to train entrance of students to spiritual } \\
\text { states of consciousness, to train muscle relaxation and slow breathing. }\end{array}$ \\
\hline Fourth & $\begin{array}{l}\text { To train effective coping styles, to train ability to garnishing daily activities with a } \\
\text { sense of holiness, practicing relaxation. }\end{array}$ \\
\hline Fifth & $\begin{array}{l}\text { To train effective coping responses, to train mental imagery and induction, to train } \\
\text { the ability to use intellectual resources to solve problems in everyday life, relaxation } \\
\text { and slow breathing exercises. }\end{array}$ \\
\hline Sixth & $\begin{array}{l}\text { To train them to manage anger and stress, to train the participants the ability to use } \\
\text { virtue behaviors (forgiveness, gratitude and abundance), to practice relaxation and } \\
\text { slow breathing. }\end{array}$ \\
\hline Seventh & $\begin{array}{l}\text { Assertiveness training, positive interpersonal relationships, autonomy, learning and } \\
\text { practicing the use of virtue behavior in everyday life, relaxation and slow breathing } \\
\text { exercises. }\end{array}$ \\
\hline Eighth & $\begin{array}{l}\text { To train and teach a personal management plan and environmental mastery to the } \\
\text { participants of the program, to sum up the training sessions before the end of the } \\
\text { meeting, to take a posttest and to appreciate participants, to take a posttest from } \\
\text { participants }\end{array}$ \\
\hline
\end{tabular}

\section{RESULTS}

Mean and standard deviation of the age of participants were 16.48 \pm 1.10 , respectively and all the participants were of male gender. The descriptive statistics related to mean and standard deviation of spiritual intelligence and public health in the two groups according to pretest and posttest are mentioned in the following table. 
Effectiveness of Training of Spiritual Intelligence Components on consequences of psychological and self-esteem of Adolescents

Table 2: descriptive statistics of scores of research variables in the two groups according to pretest and post test

\begin{tabular}{|c|c|c|c|c|c|}
\hline Component & Index & \multicolumn{2}{|c|}{ Experiment } & \multicolumn{2}{c|}{ Control } \\
\cline { 3 - 6 } & & Pretest & Posttest & Pretest & Posttest \\
\hline \multirow{2}{*}{ Depression } & Average & 15.40 & 7.30 & 14.01 & 13.70 \\
\cline { 2 - 6 } & $\begin{array}{c}\text { Standard } \\
\text { deviation }\end{array}$ & 2.45 & 2.08 & 2.79 & 2.97 \\
\hline \multirow{2}{*}{ Stress } & Average & 16.35 & 8.35 & 14.70 & 14.65 \\
\cline { 2 - 6 } & $\begin{array}{c}\text { Standard } \\
\text { deviation }\end{array}$ & 3.61 & 2.66 & 1.83 & 1.95 \\
\cline { 2 - 6 } & Average & 17.80 & 8.85 & 15.05 & 15.01 \\
\hline Self-esteem & $\begin{array}{c}\text { Standard } \\
\text { deviation }\end{array}$ & 2.28 & 1.75 & 1.82 & 1.83 \\
\cline { 2 - 6 } & Average & 2.35 & 7.70 & 3.15 & 3.30 \\
\cline { 2 - 6 } & $\begin{array}{c}\text { Standard } \\
\text { deviation }\end{array}$ & 1.22 & 1.21 & 0.98 & 1.03 \\
\hline
\end{tabular}

According to table 2, the average scores of the variables of depression, anxiety and stress were decreased in the experimental group compared with the control group.

Table 3: Levene test results in order to investigate default homogeneity of variances of depression, anxiety and stress in posttest

\begin{tabular}{|c|c|c|c|c|c|}
\hline Variable & Stage & F & Df1 & Df2 & Sig. level \\
\hline Depression & Posttest & 0.567 & 1 & 38 & 0.454 \\
\hline Anxiety & Posttest & 1.324 & 1 & 38 & 0.257 \\
\hline Stress & Posttest & 0.084 & 1 & 38 & 0.773 \\
\hline Self-esteem & Post-test & 0.250 & 1 & 38 & 0.620 \\
\hline
\end{tabular}

According to table 3 , the null hypothesis on equality of variances of the two groups in variables of depression, anxiety and stress is approved. On other words, variances of the two groups is equal to each other for the variables of depression, anxiety and stress and there is no significant difference. Therefore, according to compliance with Levine defaults, the results in order to study the research hypotheses is permissible.

Table 4: results of multivariable ANACOVA on the scores of posttest with control of pretest in variables of depression, anxiety and stress

\begin{tabular}{|c|c|c|c|c|c|c|}
\hline Test & Value & F & Df & Sig. level & Squared Eta & Power \\
\hline Pylayy effect & 0.848 & 66.723 & 3 & 0.001 & 0.848 & 0.95 \\
\hline Wilks Lambda & 0.152 & 66.723 & 3 & 0.001 & 0.848 & 0.95 \\
\hline Hotelling effect & 5.560 & 66.723 & 3 & 0.001 & 0.848 & 0.95 \\
\hline Ray's largest root & 5.560 & 66.723 & 3 & 0.001 & 0.848 & 0.95 \\
\hline
\end{tabular}




\section{Effectiveness of Training of Spiritual Intelligence Components on consequences of psychological and self-esteem of Adolescents}

As mentioned in table 4 , the significance level of all the tests $(\mathrm{P}<0.001)$ shows that there are differences between the two groups in at least one of the dependent variables (depression, anxiety and stress). According to the squared eta, 0.84 percent of the observed differences among individuals is related to the impact of independent variable (i.e. intervention method). On the other hand, since statistical power is equal to 0.95 (greater than 0.80 ), sample size is admissible. The results related to the significant difference of each of the dependent variables are mentioned in the following.

Table 5: results of multivariable ANACOVA in order to investigate the effectiveness of training of spiritual intelligence components on depression, anxiety and stress in posttest

\begin{tabular}{|c|c|c|c|c|c|c|}
\hline Index & $\begin{array}{c}\text { Sum of } \\
\text { squares }\end{array}$ & Df & $\begin{array}{c}\text { Mean } \\
\text { Square }\end{array}$ & F & Sig. level & $\begin{array}{c}\text { Squared } \\
\text { Eta }\end{array}$ \\
\hline Depression & 408.901 & 1 & 408.901 & 62.160 & 0.001 & 0.621 \\
\hline Anxiety & 396.910 & 1 & 396.910 & 72.826 & 0.001 & 0.657 \\
\hline Stress & 378.225 & 1 & 378.225 & 117.279 & 0.001 & 0.755 \\
\hline Self-esteem & 207.025 & 1 & 207.025 & 183.165 & 0.001 & 0.828 \\
\hline
\end{tabular}

Based on table 5 , since $\mathrm{p}<0.001$, the hypothesis related to the differences between depression, anxiety and stress between the two groups is approved. Moreover, it can be expressed that 0.621 percent of change in the score of depression, 0.657 percent of change in the score of anxiety and 0.755 percent of change in the score of stress is due to independent variable (training of spiritual intelligence components). Therefore, it can be expressed that training of spiritual intelligence components leads to reduction of depression, anxiety, stress and increase self-esteem in adolescents.

\section{CONCLUSION}

According to the present study on the effectiveness of training of spiritual intelligence components on depression, anxiety and stress in adolescents, the results indicated that that training of spiritual intelligence components had significant impact on depression, anxiety and stress in adolescents. This finding is in line with the studies conducted by Mirzaie Mehr (2014), Borumand Zadeh and Karimi Sani (2015), Ismailie, Ahadi, Delavar and Shafi Abadi (2007) and Shojaee and Soleimani (2015).

According to Ribbentrop (cited in Safaie et al., 2010), spirituality has relationship with health thoroughly. In addition, study of patients with chronic pains and psychological problems indicated that patients who don't trust in God and think that they are alone in such problems have no spiritual experiences and receive no religious support from religious communities. Moreover, they are not considered as religious-spiritual person and are at greater risk than other people in losing their health. In fact, it seems that lack of trust in God and negative religious coping are in close relationship with low levels of health and severe experience of pain in these patients. In addition, it can be expressed in explaining these findings that more growth of spiritual 


\section{Effectiveness of Training of Spiritual Intelligence Components on consequences of psychological and self-esteem of Adolescents}

intelligence in one's life, more trust in God, performing daily works based on knowledge and awareness, being patient in case of incorrect behavior of others, reviewing daily activities at the time of rest and relaxation and leaving bad experiences result in providing infrastructures for psychological dynamism and development, thereby one could be safe from the risk of multiple disorders. According to Wiglizurth, initiation of growth of spiritual intelligence leads to promotion of variety of skills such as emotional skills. Therefore, they can make themselves more strengthened (cited in Narimani \& Pour Esmailie, 2014). Accordingly, Hajian et al. (2012) indicated that spiritual intelligence can be used in prediction of psychological states so that most of spiritual intelligence scopes can be considered as predictors for emotional and psychological empowerment scopes. It can be expressed in explaining the finding that promotion of spiritual intelligence, which is obeying God in fact, results in improvement of social behavior, respecting mutual feelings and emotions, respecting the rights of others (i.e. strengthening the psychological states) and reduction of psychological issues and problems. Emmons (2000) defined spiritual intelligence as one of the significant factors in relation to emotional psychological issues and expressed that there is a strong relationship between spiritual intelligence and psychological and emotional empowerment and personal capabilities and abilities. In this regard, spiritual intelligence helps with promotion, enrichment and improvement of psychological and emotional capabilities.

\section{Acknowledgement}

Hereby, the authors thank the respected authorities of Education and Training Organization in Tehran Province for their assistance. Moreover, all the participants are thanked for their cooperation in the present research.

\section{REFERENCES}

Asghari, F., Ghasemi, R., Yusefi, N., Sa'adat, S. and Rafiee, F. (2015). The role of perceived stress and coping styles in Eating Disorders of high school students in Rasht in 2013, Journal of Society Health, 8 (2): 28-38.

Bayazi, M.H. (2012). Effectiveness of short-term behavioral-cognitive group therapy training on depression, anxiety and stress in patients with chronic coronary heart disease: a random controlled test. Journal of Fundamentals of Mental Health, 14 (54): 110-121.

Boroumandzadeh, N. and Karimi Sani, P. (2015). Determination of effectiveness of spiritual skills training on public health and anxiety of high school female students in Tabriz, Journal of Education and Evaluation, 8(31): 9-23.

Charkhabi M, Mortazavi A, Alimohammadi S, Hayati D. The Effect of Spiritual Intelligence Training on the Indicators of Mental Health in Iranian Students: An Experimental Study. Procedia - Social and Behavioral Sciences 2014; 159 (23): 355-358.

Delavar, A. Research Methods in psychology and educational Sciences. Tehran: Edited Press, 2007. 


\section{Effectiveness of Training of Spiritual Intelligence Components on consequences of psychological and self-esteem of Adolescents}

Emmons RA. Is spirituality an intelligence? Motivation, cognition and the psychology of ultimate concern. The international Journal for the psychology of Religion 2000; 10(1): 3-26.

Gain M, Purohit P. Spiritual intelligence: A contemporary concern with regard to living status of the senior citizens. Journal of the Indian Academy of Applied psychology 2011; 32 (3), 227- 233.

Habibpour, Z. and Sharifi, A. (2008). Comparison of depression intensity in male and female adolescents, Journal of School of Nursing and Midwifery, 7 (1): 8-12.

Hajian A, Sheikhuleslami M, Homaei R, Rahimi F, Aminoroaia M. Relationship between spiritual and spiritual intelligence. Research in Behavioral Sciences 2012, 10 (5): 500-508.

Hanifi, N., Bahraminezhad, N., Mirzaie, Khalil Abadi, T., Fazl Allah, A., Khani, M. and Taran, L. (2012). The impact of orientation program on stress, anxiety and depression in patients undergoing coronary angiography, Journal of Researches in Nursing, 7 (25), 1-8.

Henry, J, D., \& Crawford, J, R. (2005). The short-form version of the depression anxiety stress scales (Dass-21): Construct validity and normative data in a large non-clinical sample. British Journal of Clinical Psychology, 44 (2), 227-239.

Ismailie, M., Ahadi, H., Delavar, A. and Shafi Abadi, A. (2007). The impact of training of spiritual intelligence components on mental health. Journal of Clinical Psychology and Psychiatry, 13(2): 158-185.

Kazeneini, T. and Rajabi, M. (2012). Effect of cognitive-behavioral group therapy on selfesteem and assertiveness in students. Behavioral Sciences Quarterly. 4 (1): 70-83.

Kendall, P.C., Compton, S.N., Walkup, J.T., Birmaher, B., Albano, A.M., Sherrill, J., et al. (2010). Clinical characteristics of anxiety disordered youth. J Anxiety Disord. 24(3): 360-5.

Khal'atbari, J. and Aziz Zadeh Haghighi, F. (2011). The impact of life skills training and strategies of coping with mental pressure on mental health of male students, Journal of Knowledge and Research in Applied Psychology, 2 (12): 29-40.

Kheirkhah, M., Makari, H., Neysani Samani, L. and Hosseini, F. (2013). The relationship between anxiety and self-esteem in female adolescents, Center of Researches in Nursing Care, 26 (83): 19-19.

Khodabakhshi, A., Rastak, H., Mansour, L. et al. (2014). The relationship of dietary patterns with body image and anxiety in adolescents, Journal of Nursing Psychology, 2 (4): 12-25.

Legrand, J.C. (2011). The relationship between selected biographical characteristic and anxiety and depression of participants in a divorce workshop, Texas University.

Mishra P, Vashist K. A review study of spiritual intelligence, stress and well-being of adolescents in 21 century. International Journal of Research in Applied, Natural and Social Sciences 2014; 2 (4): 11-24.

Mojarrad Kahani, A.H. and Ghanavi, S. (2013). Effect of communicational skills on self-esteem in girls with somatomotor-physical disabilities. Research in Rehabilitation Sciences. 8 (3): 261-271. 


\section{Effectiveness of Training of Spiritual Intelligence Components on consequences of psychological and self-esteem of Adolescents}

Mostafaie, M.R. and Bashirian, S. (2012). Comparison study between adolescents with special diseases and healthy adolescents, Scientific Journal of School of Nursing and Midwifery, 20 (2): 65-71.

Narimani M, Ariapouran S. the study of psycho- social stressors and coping strategies and relationships to academic achievement in girl's students. Journal of psychological studies 2007; 2(3\&4): 39-59.

Narimani M, Poureslami A. Predicting changes in alexithymia of addicts from their spiritual intelligence. Journal of Fundamentals of Mental Health 2014; 16 (1): 3-11.

Rajabi, Gh.R. and Bohlul, N. (2008). Measuring reliability and validity of Rozenberg's selfesteem in first-year students of Shahid Chamran University. Educative and Psychological Researches. 3 (2): 33-48.

Safaee Rad I, Karimi L, Shamosi M, Ahmadi Tahor M. The relationship between spiritual wellbeing with mental health in college students. Journal of Sabzevar University of Medical Sciences 2010; 17 (4): 274-280.

Safar Alizadeh, F., Partov Azam, H. and Habibpour, Z. (2010). Correlation between depression and body mass index in female adolescents in Khouy, Journal of Rafsanjan School of Nursing and Midwifery, 5 (1): 17-24.

Shojaee, A. and Soleimani, I. (2015). Study of the impact of spiritual intelligence training on psychological well-being and its components in students covered by Imam Khomeini Relief Committee in Ardabil, Journal of School Psychology, 4 (1): 104-121.

Subramaniam M, Panchanatham N. Relationship between Spiritual intelligence, Spiritual Intelligence and Wellbeing of Management Executives. Global Journal for Research Analysis 03/2014; 3(3):94. DOI: 10.15373/22778160/MAR2014/32.

World Health Organization. (2009). Available from: URL: http://www.WHO.int/topics/adolescent health/en, Accessed 16 June 2009.

Yusoff MSB. Stress, stressors and coping strategies among secondary school students in Malaysian government secondary school: initial findings. Asian journal of psychiatry 2010; 11(2): 1- 15.

How to cite this article: L Ganjavi (2016), Effectiveness of Training of Spiritual Intelligence Components on consequences of psychological and self-esteem of Adolescents, International Journal of Indian Psychology, Volume 3, Issue 3, No. 7, DIP: 18.01.127/20160303, ISBN: 978$1-365-12175-3$ 